\title{
A COLABORAÇÃO NA APRENDIZAGEM DE ESCRITA DAS LÍNGUAS DE SINAIS (ELIS): O QUE PENSAM ALUNOS OUVINTES SOBRE O TRABALHO EM PARES?
}

Collaboration in the learning of sign languages writing (ELiS): What do hearing students think about working in pairs?

\author{
Guilherme Gonçalves de FREITAS - UFG ${ }^{1}$ \\ Francisco José Quaresma de FIGUEIREDO - UFG ${ }^{2}$ \\ Artur Moraes da COSTA - UFG
}

\begin{abstract}
RESUMO: Esta pesquisa, de caráter qualitativo, tem por objetivo verificar os benefícios da aprendizagem colaborativa durante a produção de textos escritos em Escrita das Línguas de Sinais (ELiS). Adotamos, como eixo orientador deste estudo, teorias sobre interação e sobre a aprendizagem colaborativa de línguas, e a investigação ocorreu na Universidade Federal de Goiás (UFG) com 6 alunos ouvintes do curso de licenciatura em Letras: Libras. Os instrumentos utilizados para coleta de dados foram: entrevistas e gravações de áudio e vídeo das interações das quais os estudantes participaram. Assim, buscamos responder às seguintes perguntas: 1) Quais as percepções dos alunos quando escrevem em ELiS individualmente e quando escrevem com o colega?; 2) De que forma a produção de texto, numa perspectiva colaborativa, pode ajudar os alunos na escrita em ELiS? Os resultados mostram que, durante a produção em pares, os alunos mencionaram mais pontos positivos do que negativos, como por exemplo: oportunidade de troca de conhecimento; possibilidade de aumento da autoestima na aprendizagem de ELiS; oportunidade de correção e reflexão, entre outros. Desse modo, concluímos que a utilização da abordagem colaborativa durante as aulas de ELiS tem o potencial para criar um ambiente positivo para aprendizagem.
\end{abstract}

PALAVRAS-CHAVE: Aprendizagem Colaborativa de línguas; Interação; Produção de Textos; Escrita de Sinais; Libras; Escrita.

\begin{abstract}
This research is a case study of a qualitative method and aims to verify the benefits of collaborative learning during the production of texts written in Sign Language Writing (ELiS). We used, as the basis for this study, theories about interaction and collaborative learning of languages, and the investigation took place at the Universidade Federal de Goiás (UFG) with 6 hearing students who took Letras: Libras as a major. The instruments used for
\end{abstract}

\footnotetext{
${ }^{1}$ Graduado em Letras: Libras e Especialista em Linguística das línguas de sinais pela Universidade Federal de Goiás. Atualmente, é mestrando em Estudos Linguísticos pela mesma instituição e graduando do curso de Pedagogia Bilíngue pelo Instituto Federal e Goiás. Membro do Grupo de Pesquisa Educação bilíngue e ensino/aprendizagem das línguas de sinais, no qual desenvolve estudos sobre ensinoaprendizagem de Libras/ELiS, formação de professores, inclusão, entre outros. E-mail: guilhermefreitaslibras@gmail.com.

2 Pós-doutor em Linguística Aplicada pela Universidade Federal de Minas Gerais. E-mail: fquaresma@terra.com.br.

3 Mestrando em Estudos Linguísticos pela Universidade Federal de Goiás. E-mail: arturmoraescosta@gmail.com.
} 
data collection were: interviews and audio- and video-recordings of the interactions the students took part in. For this study, we seek to answer the following questions: 1) What are the students' perceptions when they write in ELiS individually and when they write with their colleague?; 2) How can text production, in a collaborative perspective, help students in writing in ELiS? The results show that, during peer production, the students mentioned more positive than negative points, such as: opportunity to exchange knowledge; possibility of increasing self-esteem when learning ELiS; opportunity for correction and reflection, among others. Thus, we conclude that the use of a collaborative approach during ELiS classes has the potential to create a positive environment for learning.

KEY-WORDS: Collaborative language learning; Interaction; Texts Production; Sign writing; Libras; Writing.

\section{CONSIDERAÇÕES INICIAIS}

A Língua Brasileira de Sinais $^{4}$ (Libras), em sua modalidade escrita, tem feito parte da rotina acadêmica de vários cursos de Letras: Libras. No contexto da Universidade Federal de Goiás (UFG), tem-se adotado o sistema de escrita das línguas de sinais (ELiS). O processo de ensino-aprendizagem da ELiS tem despertado a nossa atenção a partir de aspectos relevantes trazidos por alunos do curso de licenciatura em Letras: Libras da UFG.

Alguns desses aspectos incluem a novidade do sistema de escrita na vida dos alunos surdos e ouvintes, uma vez que a grande maioria não está acostumada com a representação escrita da Libras. Além disso, outro fator que merece atenção é a existência de crenças que são originadas em conversas informais entre alunos que já estudaram ELiS em anos anteriores. Muitos desses alunos propagam suas crenças com falas do tipo: é muito difícil; é complexa; demanda muito tempo para aprender; entre outras. Da mesma forma, surgem fatores sócio-históricos, de raízes mais profundas, que apontam a criação do código ELiS como um elemento de continuísmo da dominação ouvinte, conhecido como ouvintismo ${ }^{5}$.

Outra questão que deve ser levantada no processo de ensino-aprendizagem da ELiS é o fato de que alguns alunos possuem históricos de aprendizagem da escrita da língua portuguesa de forma muito opressiva, mecânica, pouco significativa e aplicável

\footnotetext{
${ }^{4}$ Neste estudo, entende-se por sinais a "combinação do movimento das mãos com um determinado formato em um determinado lugar, podendo este lugar ser uma parte do corpo ou um espaço em frente ao corpo" (FELIPE, 2001, p. 20) para representar palavras em línguas de sinais.

5 O termo ouvintismo é explicado por Skiliar (1998, p. 15) como um "conjunto de representações dos ouvintes, a partir do qual o surdo está obrigado a olhar-se e narrar-se como se fosse ouvinte".
} 
REVISTA X, Curitiba, volume 14, n.4,p. 277-299, 2019

para a vida. Essas experiências vivenciadas durante todo o processo educacional, em muitos casos, contribuem para a construção de uma baixa autoestima dos aprendizes em contato com uma nova modalidade de escrita. Por estas razões, alguns alunos criam resistência quanto à aceitação da aprendizagem de ELiS.

Essas crenças, mencionadas sobre a aprendizagem da ELiS, são sintomas que merecem um olhar mais aprofundado por parte de professores e pesquisadores. Com o surgimento da escrita de sinais ${ }^{6}$ no Brasil, é preciso pensar em metodologias de ensino que busquem responder a alguns questionamentos, como, por exemplo: Que abordagem utilizar?; Que estratégias assumir diante dos desafios do ensino de escrita de sinais?; Que métodos aplicar para gerar compromisso dos alunos com a aprendizagem? Que ferramentas usar para promover a autoestima dos aprendizes?

A partir dessas inquietações, trazemos reflexões sobre a relevância da abordagem $^{7}$ colaborativa para o ensino de escrita de sinais, em específico, da ELiS. A escolha dessa abordagem justifica-se pelo caráter comunicativo e colaborativo que ela propõe durante as interações entre os alunos na realização de tarefas em pares (FIGUEIREDO; OLIVEIRA, 2017; GOMES; RIOS; OLIVEIRA, 2017). Gomes, Rios e Oliveira (2017, p. 102) acrescentam que "as atividades em grupos geram interação por meio da conversação face a face, da negociação de significado, da adoção de diferentes papéis, entre outros aspectos". De acordo com esses autores, trabalhar em grupos tem ainda o potencial de tornar os alunos mais responsáveis e autônomos (GOMES; RIOS; OLIVEIRA, 2017).

Há várias pesquisas no Brasil mencionando os benefícios da abordagem colaborativa na produção de textos em línguas orais (ALMEIDA; MEGID, 2017; ARAÚJO; FIGUEIREDO, 2015; CARVALHO, 2002; 2010; RODRIGUES, 2006; WOBETO, 2012), mas ainda são poucas as pesquisas que investigam a relevância da colaboração na produção de textos em escrita de sinais. Dessa forma, esta pesquisa tem por objetivo verificar como a colaboração pode ajudar os alunos durante a produção escrita em ELiS, bem como entender as estratégias que utilizam durante o processo de

\footnotetext{
${ }^{6}$ No Brasil, há quatro modalidades de escrita de sinais, todas elas apresentam códigos específicos, com exceção do sistema de escrita VisoGrafia, que contém símbolos do sistema de escrita SignWriting (SW) e da Escrita das Línguas de Sinais (ELiS). Além disso, há também o Sistema de Escrita da Língua de Sinais (SEL). Neste estudo, optamos por utilizar a ELiS durante as aulas, por ser a escrita trabalhada no curso de Licenciatura em Letras: Libras na UFG.

${ }^{7}$ Para mais detalhes sobre as diversas abordagens de ensino de línguas, veja, por exemplo, Figueiredo e Oliveira (2017).
} 
REVISTA X, Curitiba, volume 14, n.4,p. 277-299, 2019

escrita. Objetiva também apreender as percepções que esses alunos têm quando escrevem textos em ELiS individualmente e quando escrevem em pares.

Sendo assim, buscamos responder a duas perguntas: 1) Quais as percepções dos alunos quando escrevem em ELiS individualmente e quando escrevem com o colega?; 2) De que forma a produção de texto, numa perspectiva colaborativa, pode ajudar os alunos na escrita em ELiS?

Nosso estudo ${ }^{8}$ está estruturado da seguinte forma: na segunda seção abordamos, brevemente, o surgimento da escrita e a criação do sistema ELiS. Em seguida, aprofundamos a discussão sobre interação e aprendizagem colaborativa. Na terceira seção, apresentamos a metodologia do estudo e, na quarta, analisamos os dados obtidos durante a coleta. Por fim, apresentamos algumas considerações sobre os resultados desta pesquisa.

\section{DO SURGIMENTO DA ESCRITA À MODALIDADE EM ELiS}

O surgimento da escrita na história da humanidade foi um marco importante para a disseminação do saber. Antes de ela aparecer, o homem se expressava por meio de símbolos pintados em pedras, cavernas, árvores, folhas, entre outras formas de registro. Foi a partir dessas criações simbólicas, ainda no período da pré-história, que o homem descobriu outras maneiras de contar a sua trajetória e torná-la acessível por meio da escrita (BAJARD, 2002; CHARTIER, 2000; HIGOUNET, 2003).

A escrita é uma ferramenta muito utilizada no âmbito educacional, visto que os professores fazem uso dela para ensinar um conteúdo, e os aprendizes a usam para registrar uma explicação dada em sala ou para realizar tarefas (ARAÚJO; FIGUEIREDO, 2015; FIGUEIREDO, 2006; FREITAS, 2016; FREITAS; FIGUEIREDO, 2019).

A ELiS foi criada para padronizar e representar as línguas de sinais em sua forma escrita. Mariângela Estelita Barros, criadora desse sistema, observava que, durante as aulas, no curso de Libras que fazia, os alunos pouco registravam o conteúdo em sala, e quando registravam, utilizavam-se de rabiscos criativos para lembrar os sinais ensinados pelo professor (BARROS, 2015, FREITAS; FIGUEIREDO, 2019). De

\footnotetext{
${ }^{8}$ Este estudo está inserido na pesquisa intitulada Estudos sobre os efeitos da colaboração no processo de ensino-aprendizagem de línguas em contextos presenciais e virtuais, sob a responsabilidade do Professor Doutor Francisco José Quaresma de Figueiredo, um dos autores deste artigo. A referida pesquisa foi aprovada no Comitê de Ética em Pesquisa (CEP) da Universidade Federal de Goiás, com o parecer de $\mathrm{n}^{\circ}$ 2.363.676.
} 
REVISTA X, Curitiba, volume 14, n.4,p. 277-299, 2019

acordo com a autora, a anotação feita em sala era "muito extensa e inexata, pois precisaria ser uma descrição em português, um desenho, ou algo que servisse de recurso mnemônico para o que estava aprendendo com grande dificuldade" (BARROS, 2015, p. 16).

A partir das dificuldades de registro dos sinais na aprendizagem de Libras, Barros criou a ELiS em 1998. Enquanto sistema linguístico, a ELiS tem símbolos gráficos chamados de visografemas. Esses símbolos são motivados pelos critérios de visualidade e representatividade e contêm 95 unidades, sendo eles: a configuração de dedos (CD); a orientação da palma (OP); o ponto de articulação (PA) e o movimento (M). A CD contém 10 visografemas e refere-se à forma que os dedos tomam para representar o sinal. A OP contém 6 visografemas e diz respeito à posição inicial da palma, podendo estar para cima, para baixo, para medial, para distal, para trás ou para frente. O PA contém 35 visografemas e refere-se ao local de realização do sinal, podendo acontecer em diversos lugares do corpo ou no espaço. O M contém 44 visografemas e faz referência à forma de deslocamento do tronco, do braço, do dedo, do punho, das expressões faciais e corporais. Como regra ${ }^{9}$ básica da ELiS, o sinal deve ser escrito na seguinte ordem: CD, OP, PA, M, e registrado na posição horizontal e linear (BARROS, 2015, FREITAS; FIGUEIREDO, 2019).

De modo a entender a representação desse sistema, observemos o sinal /DOCE/ e sua representação em ELiS:

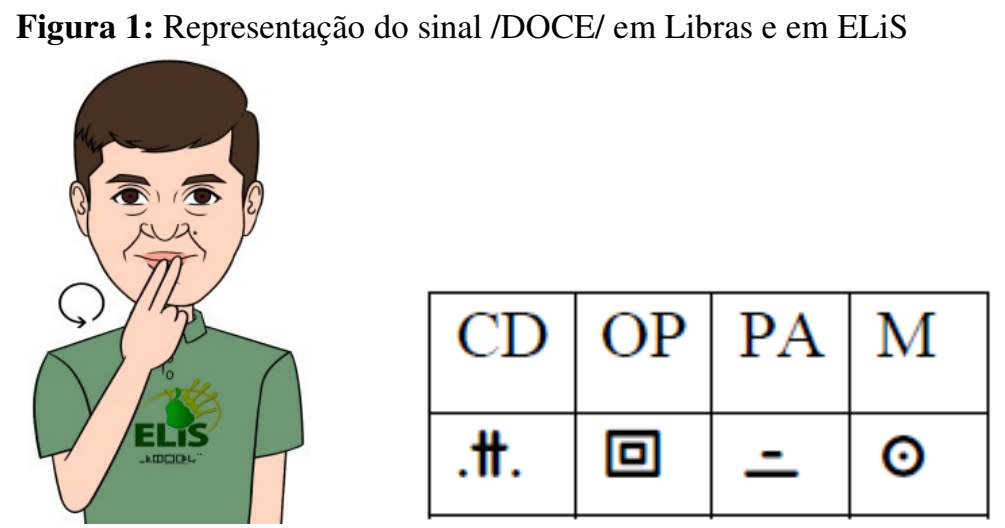

Fonte: Os autores.

\section{A ABORDAGEM COLABORATIVA E SUAS CONTRIBUIÇÕES PARA O ENSINO DA ELIS}

\footnotetext{
${ }^{9}$ Para maior detalhamento do sistema e as regras da ELiS, veja, por exemplo, Barros (2015) e Freitas (2016).
} 
REVISTA X, Curitiba, volume 14, n.4,p. 277-299, 2019

Cada vez mais, pesquisadores e professores têm procurado refletir sobre a melhor maneira de ensinar línguas, alternando seus enfoques entre a abordagem estruturalista e a comunicativa. A primeira prioriza o ensino da estrutura da língua (fonética, fonológica, morfológica, sintática, entre outras), e a segunda prioriza o uso da língua em processos significativos de mediação (FIGUEIREDO; OLIVEIRA, 2017).

Para Vygotsky (2007, p. 87), a aprendizagem é considerada "um processo puramente externo" e ocorre na mediação através de instrumentos, tais como: o uso da linguagem por explanação do professor - seja oral ou escrita; das interações ocorridas em sala de aula ou fora dela; dos livros didáticos, entre outros.

Estudos apontam para os benefícios da mediação, tanto no ensino-aprendizagem de línguas, quanto nas relações dos sujeitos em contexto social. Para Vygotsky (2007), o contexto social é parte importante no processo de coconstrução do conhecimento, isto é, o desenvolvimento cognitivo é resultado da interação entre os sujeitos. Em se tratando do ensino de segunda língua (L2), Hall (2001), Hatch (1978) e Paiva (2014) afirmam que a interação é necessária para que os alunos possam construir enunciados, bem como para negociar conteúdos, formas e significados durante a aprendizagem. Numa abordagem sociocultural, é a partir de interações que o conhecimento é adquirido (BASSI, 2006; CANDIDO JUNIOR, 2006; FIGUEIREDO, 2006; PAIVA, 2014; VYGOTSKY, 2007; WOBETO, 2012). A interação possibilita, aos seres humanos, oportunidades tanto para serem expostos a input quanto para produzirem na língua que estão adquirindo ou aprendendo (output).

A teoria do input compreensível, defendida por Krashen (1978), explica que somente adquirimos língua quando compreendemos a mensagem. Para Wobeto (2012, p. 26) “o input é representado por qualquer tipo de informação, seja ela oral (fala do colega ou do professor) ou escrita (textos, livros etc.), a qual os aprendizes de L2/LE são expostos". O input compreensível também pode ocorrer em contextos de aprendizagem de língua de sinais. Isso acontece quando os alunos, em situação de interações, utilizam algumas estratégias, tais como: gestos; repetições; apontamentos, entre outras formas de facilitar a compreensão do enunciado (OLIVEIRA-SILVA, 2017; SILVA, 2012).

Embora Krashen (1978) defenda a importância do input compreensível, há autores que afirmam, por exemplo, que receber apenas informações adequadas não possibilita aprendizagem (PAIVA, 2014; SWAIN, 1985). Uma das principais críticas à teoria do input foi feita por Swain (1985). A autora menciona que não basta fornecer 
apenas input, pois é necessário que os aprendizes tenham a oportunidade de falar, de produzir língua (output). Assim, eles têm a oportunidade de interiorizar a língua que estão aprendendo e de fazer reflexões metalinguísticas sobre ela.

Wobeto (2012, p. 27) afirma que "o output consiste em uma atividade cognitiva do indivíduo de forma a externalizar o pensamento, podendo este ser realizado por meio da fala ou da escrita". Swain (1985) apresenta três importantes funções do output na aprendizagem de línguas, sendo elas: a) testagem de hipóteses; b) função metalinguística e c) percepção (noticing).

Wobeto (2012, p. 28) definiu esses conceitos da seguinte forma.

A) testagem de hipóteses: ao produzir a fala ou a escrita, o aprendiz tem a possibilidade de testar hipóteses referentes à língua-alvo, testando, assim, a compreensibilidade por meio do feedback gerado por seu interlocutor. B) função metalinguística: [...] permite aos aprendizes refletir sobre a língua a qual estão aprendendo, possibilitando discussões sobre a forma, o significado e a função da língua no conteúdo em que se realiza a interação. C) percepção (noticing): durante a produção linguística na língua-alvo, o aprendiz pode perceber uma lacuna existente entre o que ele quer dizer e o que ele consegue dizer, contribuindo para que percebam o que ainda não sabem em L2/LE (grifos nossos).

Além disso, outra função do output foi identificada na pesquisa de doutorado de Suelene Silva (2012). A pesquisadora identificou a quarta função do output, ou seja, a repetição. De acordo com a autora, os aprendizes repetem palavras como uma forma de processar e internalizar a língua-alvo. Silva (2012) menciona que, quando os alunos estão aprendendo uma língua, é normal que eles estejam centrados na repetição da fala do colega ou de si mesmo.

Para o ensino de segunda língua, é necessário que o docente leve em consideração essas concepções e adote abordagens colaborativas, em busca de um ensino reflexivo na promoção de aprendizes autônomos em seus processos de aprendizagem (ARAÚJO; FIGUEIREDO, 2015; CARVALHO, 2012; FIGUEIREDO, 2001, 2006; FREITAS; FIGUEIREDO, 2019; OLIVEIRA-SILVA, 2017; PIRES, 2014; REZENDE, 2014; TORRES; IRALA, 2014; WOBETO, 2012).

A aprendizagem colaborativa é uma situação em que dois ou mais aprendizes estão envolvidos em um processo de aprendizagem, de coconstrução do conhecimento, que ocorre a partir de interações realizadas face a face ou intermediadas por meio de ferramentas midiáticas (FIGUEIREDO, 2001, 2005, 2006). 
REVISTA X, Curitiba, volume 14, n.4,p. 277-299, 2019

Torres e Irala (2014) afirmam que essa abordagem vai além do ensino tradicionalista, ou seja, passa a considerar outras variáveis metodológicas a despeito da explicação dada pelo professor. A aprendizagem, nesse sentido, considera que toda construção de conhecimento é auxiliada por ações coletivas, isto é: aluno ensinando aluno; aluno ensinando professor e professor ensinando aluno.

Os autores acrescentam que a aprendizagem colaborativa pode:

promover uma aprendizagem mais ativa por meio do estímulo: ao pensamento crítico; ao desenvolvimento de capacidades de interação; à negociação de informações e resolução de problemas; ao desenvolvimento da capacidade de autorregulação do processo de ensino-aprendizagem. (TORRES; IRALA, 2014, p. 61).

As pesquisas qualitativas e quantitativas apontam para os benefícios da colaboração, sendo elas: troca de conhecimento; reflexão sobre enunciados, seja oral, sinalizado ou escrito; diminuição da quantidade de erros na produção dos textos; promoção da autonomia ao corrigir o colega; aumento da autoestima dos alunos; ajuda na resolução de problemas; promoção da segurança durante a realização das tarefas; e diminuição da ansiedade de aprendizes iniciantes, entre outros (BASSI, 2006; CARVALHO, 2002; CANDIDO JUNIOR, 2006; FIGUEIREDO, 2001, 2006; FIGUEIREDO; ASSIS, 2006; FREITAS, 2016; FREITAS; FIGUEIREDO, 2019; PIRES, 2014; REZENDE, 2014; WOBETO, 2012).

Wood, Bruner e Ross (1976) afirmam que aprendizes iniciantes apresentam comportamentos de ansiedade quando estão aprendendo uma segunda língua. De acordo com Crandal (1999, p. 227), a colaboração poderá reduzir "a ansiedade negativa, aumentando a motivação, facilitando o desenvolvimento de atitudes positivas com relação à língua e à sua aprendizagem". Isso ocorre devido ao fato de os aprendizes utilizarem estratégias de apoio durante a realização das tarefas.

Wood, Bruner e Ross (1976) cunharam a metáfora do scaffolding ${ }^{10}$ para representar o apoio dado por um colega mais experiente a um menos experiente para, juntos, resolver as tarefas. O scaffolding pode ocorrer de várias formas, tais como: o uso da língua materna (L1); o uso de ferramentas digitais (computador, celular etc.); o uso

\footnotetext{
${ }^{10}$ Wood, Bruner e Ross (1976) apresentam o conceito de scaffolding como um mecanismo no qual uma pessoa ajuda a outra a realizar uma tarefa sozinha que estaria fora do seu alcance. De acordo com Donato (1994, p. 40) "na interação social um participante experiente pode criar, por meio da fala, condições de apoio nas quais o aprendiz pode participar e ampliar suas habilidades e conhecimentos para níveis mais altos de competência".
} 
REVISTA X, Curitiba, volume 14, n.4,p. 277-299, 2019

de imagens; apontamento visuogestual; e o uso da escrita (FIGUEIREDO, 2001; OLIVEIRA-SILVA, 2017; PIRES, 2014; WOBETO, 2012).

Apesar dos benefícios da aprendizagem colaborativa, aqui apresentados, alguns estudos apontam possíveis problemas em relação a essa abordagem, tais como: conflitos durante as interações; divergências de perfil; entraves de comunicação; autonomia excessiva de um par e a falta de confiança na informação do outro, entre outros (CARVALHO, 2002; FIGUEIREDO, 2001, 2005, 2006; WOBETO, 2012).

Após discutir sobre os principais conceitos teóricos, passemos à metodologia utilizada na realização deste estudo.

\section{O ESTUDO}

Esta pesquisa é um estudo de caso qualitativo (FIGUEIREDO, 2001; MOREIRA; CALEFFE, 2008). A escolha desse método justifica-se pelo pequeno número de participantes envolvidos na pesquisa e, também, pelo fato de os dados terem sido gerados em um contexto específico, o da sala de aula.

A pesquisa ocorreu durante o primeiro semestre de 2018, em uma turma de vinte alunos matriculados na disciplina de Introdução à Escrita das Línguas de Sinais (ELiS), que cursavam o $3^{\circ}$ período de Licenciatura em Letras: Libras, na UFG. Os participantes são seis alunos ouvintes, que formaram três pares, definidos pelos seguintes pseudônimos: Amanda e Vanessa; Natasha e Gabriel; Ricardo e Barrios.

Como instrumentos para a coleta de dados, foram utilizadas entrevistas gravadas em áudio e duas câmeras para registrar as interações entre os alunos, ocorridas em língua portuguesa e em Libras. Para a transcrição desses dados, foram utilizados algumas simbologias, com base em Figueiredo (2001): (itálico) - indica uma descrição feita por nós sobre o comportamento dos alunos quando sinalizam e discutem sobre a estrutura do sinal em Libras; ... - indica pausa quando os alunos estão falando.

Para a coleta dos dados, foi proposta uma tarefa de produção escrita, que teve duração aproximada de três horas. Inicialmente os alunos receberam instruções sobre como deveriam escrever uma carta convite ${ }^{11}$ tanto em português quanto em ELiS. Essa tarefa teve por objetivo convidar alunos do Ensino Médio a participar do Espaço das Profissões $^{12}$, e cada par recebeu uma folha de rascunho. Após realizarem a produção, os

\footnotetext{
${ }^{11}$ No Apêndice A, apresentamos o texto escrito pelos participantes Natasha e Gabriel, tanto em português quanto em ELiS.

${ }^{12} \mathrm{O}$ Espaço das Profissões é um evento que acontece anualmente na UFG e tem por objetivo convidar alunos do Ensino Médio e Fundamental a conhecer os cursos oferecidos pela Universidade.
} 
REVISTA X, Curitiba, volume 14, n.4,p. 277-299, 2019

participantes foram entrevistados em português pelo primeiro autor deste texto e puderam contrastar a experiência de produzir textos em ELiS individualmente e colaborativamente.

\section{RESULTADOS}

A análise dos dados tem por objetivo responder às duas perguntas apresentadas na introdução deste artigo: 1) Quais as percepções dos alunos quando escrevem em ELiS individualmente e quando escrevem com o colega?; 2) De que forma a produção de texto, numa perspectiva colaborativa, pode ajudar os alunos na escrita em ELiS?

A análise das entrevistas, realizadas com os participantes, revelou pontos positivos e negativos sobre trabalhar individualmente e colaborativamente, conforme pode ser observado no quadro a seguir:

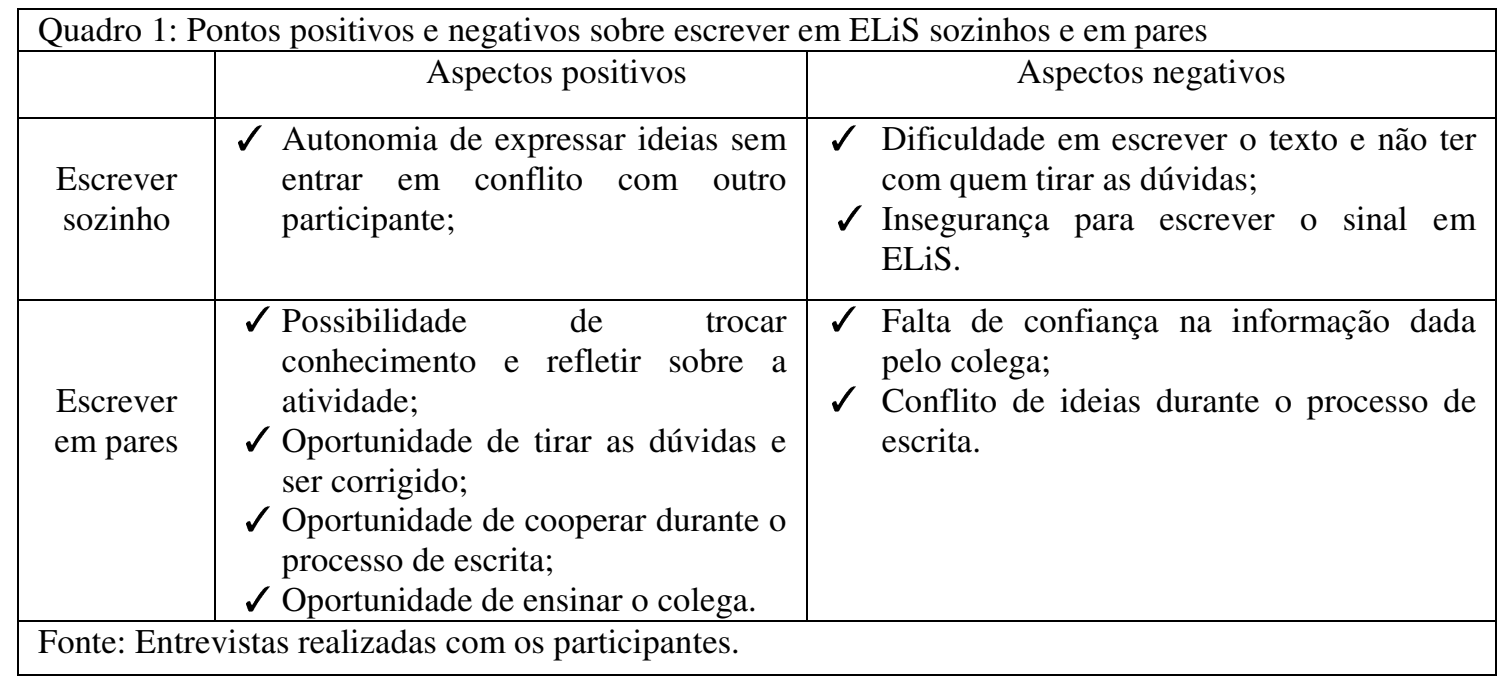

Apresentamos, a seguir, algumas das percepções positivas dos participantes sobre escrever individualmente.

\section{Autonomia de expressar ideias sem entrar em conflito com outro participante.}

Apenas quatro dos participantes mencionaram pontos positivos sobre escrever em ELiS individualmente. Para Natasha, trabalhar sozinha faz com que ela tenha autonomia sobre as ideias que irá aparecer no texto escrito. Vanessa, por sua vez, afirma que escrever individualmente gera menos conflitos de ideias. Ela afirma, por exemplo, que, durante a atividade realizada, ela e sua parceira discordaram sobre alguns aspectos linguísticos da Libras e da ELiS, conforme ilustrado a seguir: 
[1] Natasha:

$\mathrm{Eu}$ prefiro escrever individualmente, porque você vai pelo seu conhecimento, pelas suas ideias, né?! Quando o trabalho é realizado em dupla, é muita cabeça pensando, muita ideia querendo sobrepor à outra, e às vezes isso não dá muito certo. Eu gosto de fazer sozinha porque faço as coisas no meu tempo.

[2] Vanessa: Então... trabalhando sozinha, você entra menos em conflito. A gente acabou entrando em conflito para escrever alguns sinais (referindo-se a quando escreveu com a colega). Por exemplo, se a palma da mão era para frente ou para trás. Ela faz o sinal de um jeito e eu faço de outro... Mas eu vejo mais pontos positivos trabalhando em conjunto do que pontos negativos. É tipo duas cabeças pensando, sabe?! Alguns sinais que eu não sei ela já sabe, e isso facilita para escrever em ELiS, né?

Vanessa menciona que "trabalhar sozinha gera menos conflito" de ideias. No entanto, a participante não deixa de relatar pontos positivos quando trabalhou com Amanda. É preciso levar em consideração que todos esses conflitos fazem parte do processo de aprendizagem, pois é a partir dessas discussões que os alunos têm a oportunidade de falar, refletir e testar hipóteses sobre a língua-alvo, conforme afirmam Swain (1985) e Paiva (2014).

Embora as participantes tenham mencionado pontos positivos sobre trabalhar individualmente, elas afirmaram ter dificuldades quando trabalham sem a ajuda de um colega. Essas dificuldades foram amenizadas quando tiveram o apoio do seu par, como podemos observar nos trechos 3,4 e 5

[3] Natasha:

Pesquisador:

Natasha:

[4] Pesquisador:

Vanessa:

[5] Pesquisador:

Vanessa:
A única dificuldade em escrever em ELiS é não saber a ordem sintática da Libras (referindo-se a ordem sujeito, verbo e objeto). Além disso, alguns sinais que eu não conheço, né? Por exemplo, eu encontro várias dificuldades por ainda não ter fluência na língua.

Entendi. E quando você estava escrevendo com o Gabriel, você acha que essas dificuldades foram amenizadas?

Sim, ajudou bastante. A vantagem de trabalhar em dupla é exatamente a possibilidade de trocar ideias. Às vezes, a pessoa sabe um sinal que você ainda não conhece, né? Ele (referindo-se a Gabriel) pôde ajudar-me nessa questão, e eu o ajudei na escrita em ELiS.

Você tem dificuldades quando escreve individualmente? Caso positivo, quais são?

A principal dificuldade que eu vejo é que ainda tenho pouco domínio da Libras. E a segunda dificuldade que eu mais sinto é ... sobre os visografemas, eu ainda não consigo memorizar todos.

E quando você estava escrevendo com a Amanda, você acha que essas dificuldades foram amenizadas?

Essas dificuldades que eu te falei amenizaram sim. Porque ela sabe todos os visografemas e é justamente nessa parte que eu tenho mais dificuldade. No geral, para mim, escrever com ela foi bem mais fácil, porque algumas coisas que eu sabia, ela não sabia, daí eu a ensinava e aprendia com ela também. 
REVISTA X, Curitiba, volume 14, n.4,p. 277-299, 2019

Os participantes mencionaram dois aspectos negativos sobre escrever textos em ELiS individualmente: dificuldade em escrever o texto e não ter com quem tirar as dúvidas; e insegurança para escrever o sinal em ELiS.

\section{Dificuldade em escrever o texto e não ter com quem tirar as dúvidas}

Segundo os participantes, as maiores dificuldades que encontram durante a produção escrita em ELiS é a falta de informações mais precisas em relação ao sistema. Essa questão provoca bloqueios, ansiedade e resultam numa aprendizagem não significativa, conforme podemos observar nos relatos de Vanessa, Gabriel e Barrios:

[6] Pesquisador: Qual é a sua opinião sobre escrever em ELiS individualmente?

Vanessa: $\quad$ Então ... eu não gosto muito de escrever texto em ELiS sozinha, por questões de sinais que não conheço, sabe? E tem alguns visografemas que eu não consigo lembrar. Então, trabalhar sozinha para mim é mais complicado.

[7] Pesquisador Você vê pontos negativos quando escreve em ELiS individualmente? Caso positivo, quais?

Gabriel O lado negativo é que sem a ajuda do colega e sem a interação, não tem com quem eu tirar dúvidas, ter uma explicação mais bem elaborada, sabe? Eu não consigo ir à frente quando estou com dúvidas. Parece que algo me bloqueia.

[8] Barrios: Então, eu acho que o único ponto negativo é justamente o de não ter interação com outras pessoas que sabem a forma correta da escrita ou de um sinal em Libras.

\section{Insegurança para escrever o sinal em ELiS}

Os relatos 9 e 10 ilustram pedidos de ajuda em relação à aprendizagem da escrita. Essas falas nos chamam a atenção para os caminhos metodológicos que nós, professores, devemos utilizar em sala de aula, ou seja, uma abordagem colaborativa por meio da qual os alunos possam aprender com o auxílio um do outro. Gabriel, por exemplo, menciona que a "insegurança em saber se está certo ou errado", quando está escrevendo sozinho em ELiS, o sufoca. O mesmo acontece com Amanda, que afirma sentir-se insegura em alguns momentos quando escreve sozinha. Por não ter com quem tirar as dúvidas, ela acaba escrevendo errado, visto que não sabe a maneira correta da representação do sinal em Libras.

[9] Pesquisador: Você tem dificuldades de escrever em ELiS sozinha?

Amanda: $\quad$ Escrever o texto sozinha para mim é muito difícil, principalmente por eu ainda não ter a fluência necessária em Libras. Então, eu fico muito confusa para saber como é a forma correta de representação do sinal (referindo-se à produção em Libras). E por não saber a forma correta, eu acabo escrevendo errado (referindo-se à escrita em ELiS). 

prejudicial para mim. Essa insegurança de saber se está certo ou errado me sufoca (referindo-se à produção escrita em ELiS). Eu não consigo desenvolver. Quando eu faço o trabalho com outra pessoa, a gente troca conhecimento e isso é muito interessante. Inclusive, em algumas atividades que fiz em grupo, contribuiu muito para o meu aprendizado. Eu vi que aprendi muito, pude ter mais confiança em mim mesmo.

Em relação ao trabalho colaborativo, realizado na aula de ELiS, vários foram os aspectos positivos, relatados por todos os alunos, conforme pudemos observar no Quadro 1. Vejamos algumas dessas percepções:

\section{Possibilidade de trocar conhecimento e refletir sobre a atividade}

Nos trechos 11 e 12, os participantes percebem que a colaboração é um momento de eles refletirem sobre a atividade como um todo. Essa é uma das características da aprendizagem colaborativa, visto que o conhecimento é compartilhado durante as interações realizadas entre os alunos, conforme mencionam Bassi (2006), Candido Junior (2006), Figueiredo (2006), Torres e Irala (2014) e Wobeto (2012).

[11] Pesquisador

Vanessa:

[12] Pesquisador

Vanessa:
Você viu pontos positivos em trabalhar colaborativamente? Caso positivo, quais?

Eu vejo muitos pontos positivos, eu jamais iria conseguir produzir uma carta em ELiS. Não sei, é coisa minha, sabe? Eu sempre gostei de trocar ideia com outros colegas, acho isso muito gratificante. Eu não tenho domínio da Libras e ela me ajudou bastante durante nossas várias reflexões sobre como era feito o sinal. Então, eu vejo como ponto positivo a troca de conhecimento que tivemos durante toda a produção do texto.

Durante essa troca de conhecimento entre você e Amanda, o que você conseguiu aprender com ela?

Então ... a gente trocou muitas dicas de como memorizar os visografemas. Ela me ajudou muito sobre o uso dos diacríticos ${ }^{13}$, por que eu estava com muita dúvida nessa parte, por exemplo: Como e onde colocar, sabe?

\section{Oportunidade de tirar as dúvidas e ser corrigido}

\footnotetext{
${ }^{13}$ Os diacríticos são usados em tamanho menor, acima, abaixo, ou à direita dos visografemas de configuração de dedos (CD), ponto de articulação (PA) ou movimento (M). No grupo de configuração de dedos, por exemplo, eles têm a função de indicar a direção da ponta dos dedos, isto é, se os dedos estão para frente, para trás, para baixo, para medial ou distal, bem como se há contato entre os dedos ou movimento das mãos. No grupo de ponto articulação, a função do diacrítico é mostrar que o sinal, em Libras, pode apresentar contato dos dedos com o ponto de articulação, bem como indicar pontos de locação simultâneos, onde uma única mão tem contato com dois PAs ou, também, mostrar o lado que o sinal está sendo realizado, por exemplo, lado direito ou esquerdo. No grupo de movimento, o diacrítico tem a função de ilustrar os movimentos com repetição contínua ou de alternância (quando a mão realiza o mesmo movimento, mas em sentidos opostos), como também mostrar os movimentos simultâneos, quando uma mão apresenta mais de um movimento. Para mais detalhes sobre o uso de diacríticos, veja, por exemplo, Barros (2008, 2015) e Freitas (2016).
} 
Nos trechos 13 e 14, os participantes relatam que a interação com o colega possibilitou-lhes descontruir hipóteses sobre algo que eles acreditavam estar correto. Os depoimentos de Ricardo e Gabriel ilustram o fato de que a interação é provida de muitos scaffoldings (CANDIDO JUNIOR, 2006; WOBETO, 2012; WOOD; BRUNER; ROSS, 1976). Essa proposta de aprendizagem, visando a uma participação com mais interatividade em sala de aula, faz com os alunos tenham mais confiança durante as tarefas, conforme afirma Rezende (2014).

[13] Pesquisador: Como foi o processo de escrever o texto em ELiS com seu colega? Você viu pontos positivos em trabalhar colaborativamente?

Ricardo: Eu achei muito relevante, porque muitas coisas eu pensava que eram de um jeito, e ele falava que não era daquele jeito, que era de outro (referindo-se à execução do sinal em Libras). Ele mostrava o sinal para mim, e eu acabava chegando a uma conclusão de que eu estava errado. Da mesma forma quando ele falava que o sinal era de uma forma, e eu falava que o sinal era de outra.

[14] Pesquisador: Você viu pontos positivos em trabalhar com Natasha? Caso positivo, quais? Gabriel: $\quad$ O ponto positivo de trabalhar com Natasha foi a oportunidade de eu tirar minhas dúvidas. Ela me ajudou muito nisso. Ela sempre estava muito interessada em me ensinar. Eu amei trabalhar com ela, pois ela sempre estava me corrigindo. Eu aprendi muita coisa que eu não sabia porque sozinho eu estava fazendo tudo errado (referindo-se ao momento de escrita quando trabalhou individualmente).

\section{Oportunidade de cooperar durante o processo de escrita}

Outro aspecto positivo, também mencionado por Vanessa, foi a oportunidade de trocar ideias durante a produção do texto. Para ela, o trabalho colaborativo permitiu que a atividade fosse menos cansativa. A colaboração, nesse sentido, conforme explicam Figueiredo (2006) e Gomes, Rios e Oliveira (2017), promove também um ambiente favorável para a aprendizagem, visto que os alunos assumem papéis mais ativos na realização das tarefas, evitando que a responsabilidade recaia apenas sobre um aprendiz, como ilustrado a seguir.

[15] Vanessa: No processo de escrita com Amanda, a gente soube trabalhar muito bem colaborativamente. Eu pude escrever um pouco, ela escrevia também. Ela me ajudava nas coisas que eu não sabia. A gente discutia sobre o sinal juntas... e depois sobre o que iríamos colocar no texto. Fica muito cansativo escrever um texto sozinha, principalmente para a gente que está aprendendo ELiS agora, né? Então... por eu ter feito curso de Libras por 1 ano, eu sei mais sinais do que ela e ela sabe mais visografemas do que eu. $O$ trabalho com ela foi muito complementar, foi bem mais fácil trabalhar assim.

\section{Oportunidade de ensinar ao colega}


A realização de atividades colaborativas foi vista neste estudo como uma troca de saberes. Sendo assim, é possível identificar, na fala de Natasha, o cuidado, a satisfação e a motivação que a participante teve para ensinar Gabriel. Uma das estratégias de ensino utilizadas por ela foi o uso de perguntas indiretas, como, por exemplo: "Onde o sinal é realizado? Tem movimento? Onde está a orientação da palma? Qual a configuração dos dedos?”. Essas estratégias configuram-se como um tipo de scaffolding implícito. Conforme explicam Wood, Bruner e Ross (1976), esse processo de colaboração ajuda os alunos a se tornarem autônomos e reflexivos sobre o processo de aprendizagem da língua.

[16] Pesquisador: Você viu pontos positivos em trabalhar colaborativamente com seu colega?

Natasha: $\quad$ Eu vejo muitos pontos positivos, mas o que eu considero mais importante foi a oportunidade de ensinar ELiS para Gabriel. Ele não estava sabendo como era a ordem correta para escrever (referindo-se à ordem básica da ELiS). Ele tinha algumas dificuldades quanto ao uso dos visografemas, daí eu sempre perguntava para ele: Que movimento é esse? Onde o sinal é realizado? Tem movimento? Onde está a orientação da palma? Qual a configuração dos dedos? Eu considero muito positivo isso, pois ensinando eu aprendo mais.

Apesar dos pontos positivos, levantados até aqui, dois aspectos negativos foram mencionados pelos participantes sobre trabalhar em pares: o conflito de ideias durante o processo de escrita, já explicitado no trecho 2, na fala de Vanessa; e a falta de confiança na informação dada pelo colega.

\section{Falta de confiança na informação dada pelo colega}

No trecho 17, podemos identificar que a falta de confiança no colega pode ocasionar certo incômodo durante o processo de colaboração. Amanda não sente confiança nas informações dadas pela colega e, quando dialoga com ela, não tem o apoio necessário, como podemos observar a seguir.

[17] Pesquisador: Você viu pontos negativos em trabalhar colaborativamente com seu colega? Caso positivo, quais?

Amanda: $\quad$ Como ponto negativo, vamos supor que se eu fazia um sinal, e a Natasha fazia um sinal diferente. Aí, ela sempre falava: "ah, faz do jeito que você sabe". Então eu acabava não tendo muita confiança no que ela passava para mim. Isso, às vezes, atrapalha. Não sei se é por conta da falta de confiança mesmo, de não saber, ou por não querer me contrariar.

\footnotetext{
DE QUE FORMA A PRODUÇÃO DE TEXTO, NUMA PERSPECTIVA COLABORATIVA, PODE AJUDAR OS ALUNOS NA ESCRITA EM ELIS?
} 
Nesta seção, apresentamos os resultados referentes às interações ocorridas entre os alunos, bem como as estratégias mediadoras utilizadas por eles durante o processo de escrita. As principais estratégias identificadas neste estudo foram o uso de scaffolding e trocar ideias sobre a tarefa a ser executada.

Os participantes relataram que, trabalhando juntos, puderam compartilhar ideias, debater estratégias a serem utilizadas e discutir sobre a forma correta do sinal em Libras/ELiS. Esses aspectos enfatizam os benefícios da aprendizagem colaborativa (BASSI, 2006; CANDIDO JUNIOR 2006; CARVALHO, 2002, 2012; FIGUEIREDO, 2006; WOBETO, 2012).

Podemos observar, no trecho 18, que a estratégia utilizada por Natasha e Gabriel serviu para mediar a realização da tarefa, pois eles puderam observar, refletir e criar meios para facilitar a escrita do sinal em ELiS.

Gabriel: $\quad$ Eu gostei muito de fazer o trabalho com a Natasha, porque ela tem muito conhecimento da matéria. Isso me ajudou bastante. Durante o processo de escrita, o que nos ajudou foi isso, ela tem muito conhecimento de ELiS, e eu conheço muitos sinais da Libras. Acabou que complementou (referindo-se ao conhecimento de ambos). Além disso, outra estratégia que utilizamos foi mostrar o sinal (referindo-se à produção sinalizada em Libras), ela mostrava para mim, eu mostrava para ela, isso nos ajudou a escrever a posição da mão, da orientação da palma, do ponto de articulação e do movimento. A maioria das dúvidas que eu tinha, ela sabia me atender e vice-versa. Nosso trabalho foi desenvolvido com maior praticidade e menor tempo possível.

A estratégia utilizada pelos participantes é um fator que deve ser levado em consideração nas aulas de Libras. Aprendizes iniciantes encontram barreiras para aprendizagem dessa língua, uma vez que a modalidade linguística requer mais atenção por ser visuoespacial. Dessa forma, utilizar metodologias colaborativas pode ser uma alternativa para que os alunos criem estratégias para solucionar problemas encontrados durante o processo de escrita em ELiS.

No trecho 19, as participantes Vanessa e Amanda conversam sobre o movimento do sinal /LIBRAS/. Vanessa assume o papel de escrever o sinal, enquanto Amanda colabora com sua colega, identificando possíveis erros na escrita em ELiS, conforme podemos observar a seguir:

[19] Vanessa: Libras [...] (momento em que Vanessa sinaliza o sinal /LIBRAS/ e pensa sobre a forma correta para escrever o sinal)

Amanda: $\quad$ Todas as mãos abertas...

Vanessa As duas palmas para medial, no espaço neutro, movimento repetido e alternado (referindo-se à realização do sinal no espaço frente ao corpo, a palma das mãos frente à outra, com a ponta dos dedos para cima, movimento linear para frente e 
REVISTA X, Curitiba, volume 14, n.4,p. 277-299, 2019

\begin{abstract}
para trás, alternadamente)
Amanda: Como assim: repetido e alternado?

Vanessa: É, uai. Olha aqui (momento em que a participante mostra o sinal para a colega e escreve em ELiS, no papel, o tipo de movimento).

Amanda: Para frente e para trás, né?

Vanessa: (novamente a participante produz o sinal e reflete sobre ele) Ah, é o movimento do punho. Se for para frente e para trás, fica assim, né?! (produzindo o sinal com as duas mãos abertas, palma para medial e movimento para frente e para trás alternadamente).

Amanda: Exatamente! O movimento é mover o punho lateralmente (momento em que Amanda produz o sinal tendo as duas mãos abertas, palma para medial, no espaço neutro frente ao corpo e movimento de girar o punho lateralmente repetidamente).
\end{abstract}

Nesse diálogo, podemos observar várias estratégias utilizadas pelos alunos ao representar o sinal /LIBRAS/. Essas estratégias podem ser compreendidas da seguinte forma: 1) pelo uso de respostas: quando Vanessa testa hipóteses sobre os aspectos linguísticos do sinal - “As duas palmas para medial, no espaço neutro, movimento repetido e alternado"; 2) por perguntas: quando Amanda desconstrói a hipótese da colega - "Como assim, repetido e alternado?"; 3) por uma explicação mais elaborada: "É, uai. Olha aqui." e 4) por correção - "Para frente e para trás".

Todas essas estratégias levaram Amanda a perceber o erro - "Ah, é o movimento do punho". O feedback oferecido pela participante Vanessa permitiu que Amanda conseguisse compreender a forma correta do sinal. Essa é uma das contribuições do trabalho colaborativo, que permite aos alunos focar na forma do enunciado, refletir, falar e corrigir uns aos outros (BASSI, 2006; CANDIDO JUNIOR, 2006; FIGUEIREDO, 2006; SWAIN, 1985; WOBETO, 2012).

No trecho 20, Natasha e Gabriel estão escrevendo a carta convite, na modalidade escrita em português. A interação entre os alunos revela a forte presença de perguntas, visto que estão sempre dialogando: - “[...] encaminhar para os alunos?”; - "É para os alunos participarem do evento?”; - "da Faculdade de Letras?”.

Bassi (2006, p. 148) afirma que essas interações contribuem "para o melhor entendimento do assunto tratado", pois os participantes buscam apresentar informações necessárias para o esclarecimento das ideias, conforme podemos observar a seguir:

[20] Natasha: A gente tem que fazer uma carta convidando para o espaço das profissões, que acontece na UFG. Nós iremos encaminhar para os alunos?

Gabriel: $\quad$ Sim.

Natasha: Entendi. Então vamos lá.

Gabriel: É para os alunos participarem do evento?

Natasha: É. (Natasha e Gabriel iniciam o processo de escrita da carta em português) Convidamos a todos os alunos ...

Gabriel: [...] da Faculdade de Letras?

Natasha: Não! O convite é para todos os alunos. Porque o espaço das profissões é um local 
REVISTA X, Curitiba, volume 14, n.4,p. 277-299, 2019

onde todos os alunos do Ensino Médio, que vão fazer o vestibular, possam conhecer os cursos e as profissões. O evento acontece na UFG e não apenas na Faculdade de Letras.

Gabriel: Entendi.

Essa interação ilustra o caráter colaborativo que permeia a execução da tarefa quando os aprendizes trabalham juntos.

\section{CONSIDERAÇÕES FINAIS}

Com esta pesquisa, pretendemos contribuir com a área de ensino-aprendizagem de línguas de sinais, visto que os resultados encontrados enfatizam a importância de trabalharmos teorias de ensino voltadas para uma visão mais dialógica entre professores e alunos em sala de aula. Até aqui, vimos que a relação do professor de Escrita das Línguas de Sinais (ELiS), a partir da atividade de produção de texto, numa perspectiva colaborativa, proporcionou aos estudantes momento de motivação, tranquilidade, criação e (re)criação de sentenças quando estavam realizando suas tarefas.

Neste sentido, trazemos dois resultados: das interações realizadas em sala de aula, bem como das percepções dos alunos sobre escrever individualmente e colaborativamente. Os resultados mostram que a grande contribuição da aprendizagem colaborativa não está apenas na realização das atividades, mas, sim, na oportunidade de os alunos, juntos, criarem estratégias significativas durante o processo de aprendizagem de ELiS e Libras.

Assim, concordamos com Figueiredo (2005, p. 209) quando afirma que os alunos trabalhando colaborativamente têm a oportunidade "de negociar seus pontos de vistas, de refletir sobre os erros que cometem, de observar a estrutura da língua, de poder aprender com os erros e de mudar sua concepção de erro e correção".

Por meio das vozes dos alunos, verificamos pontos semelhantes aos mencionados pelo autor. Neste estudo, vimos que a realização de tarefas em pares colabora para uma aprendizagem mais significativa, com oportunidades para os alunos sentirem-se mais seguros quando estão escrevendo seus textos e tirando dúvidas sobre os sinais. Por meio das interações, verificamos que os alunos estão sempre fazendo reflexão metalinguística sobre a Libras, isto é, eles pensam sobre a estrutura em que o sinal é feito. O uso de perguntas e gestos são exemplos de estratégias bem-sucedidas utilizadas por eles. 
REVISTA X, Curitiba, volume 14, n.4,p. 277-299, 2019

Por intermédio da análise das interações e das percepções dos participantes deste estudo, concluímos que a utilização de abordagens colaborativas em contextos de produções de textos em Escrita de Sinais, em específico em ELiS, pode ser um caminho para que algumas crenças sejam descontruídas, pois há rumores de que aprender ELiS é difícil. Dessa forma, metodologias colaborativas devem ser consideradas como viáveis para o ensino dessa modalidade, visto que os alunos podem contar com o apoio do colega para suprir as possíveis dificuldades que encontram tanto para aprender ELiS quanto Libras.

\section{REFERÊNCIAS}

ALMEIDA, A. R.; MEGID, M. A. B. A. A escrita colaborativa na formação continuada de professores que ensinam matemática. Revista Inter-Ação, Goiânia, v. 42, n. 1, p. 176193, jan./abr. 2017.

ARAÚJO, M. A. F. FIGUEIREDO, F.J.Q. Interação e colaboração no processo de escrita e reescrita de textos em língua inglesa. Revista Desempenho, v. 1, n. 24, p. 1-20, 2015.

BAJARD, E. Caminhos da escrita: espaços de aprendizagem. São Paulo: Cortez, 2002.

BARROS, M. E. ELiS - escrita das línguas de sinais: proposta teórica e verificação prática. 2008. 192 f. Tese (Doutorado em Linguística) - Centro de Comunicação e Expressão, Universidade Federal de Santa Catarina, Florianópolis, 2008.

Penso, 2015.

ELiS: sistema brasileiro de escrita das línguas de sinais. Porto Alegre: Ed.

BASSI. C. E. O efeito de negociações: uma análise do processo de co-construção de textos em língua francesa. In: FIGUEIREDO. F. J. Q. de. (Org.). A aprendizagem colaborativa de línguas. Goiânia: Ed. UFG, 2006. p.143-164.

CÂNDIDO JUNIOR, A. Os processos de colaboração e de negociação durante a realização de atividades comunicativas. In: FIGUEIREDO, F. J. Q. de. (Org.). A aprendizagem colaborativa de línguas. Goiânia; Ed. da UFG, 2006. p. 47-80.

CARVALHO, G. O. Revisão colaborativa de textos escritos em língua inglesa por alunos iniciantes do curso de letras. 2002. 169 f. Dissertação (Mestrado em Linguística Aplicada) - Faculdade de Letras, Universidade Federal de Goiás, Goiânia, 2002.

CARVALHO, G. O. A influência da revisão colaborativa na produção textual em língua inglesa. Anápolis: Universidade Estadual de Goiás, 2010.

CHARTIER, R. Cultura escrita, literatura e história. Porto Alegre, Artmed, 2000. 
CRANDALL, J. J. Cooperative language learning and affective factors. In: ARNOLD, J. (Ed.). Affect in language learning. Cambridge: Cambridge University Press, 1999. p. 226-245.

DONATO, R. Collective scaffolding in second language learning. In: LANTOLF, J. P.; APPEL, G. (Ed.). Vygotskian approaches to second language learning. Norwood, N. J.: Ablex Publishing Company, 1994. p. 33-56.

FELIPE, T. A. Libras em contexto: curso básico, livro do estudante cursista. In: BRASIL. MEC, SEESP. Programa Nacional de Apoio à Educação dos Surdos, 2001.

FIGUEIREDO, F. J. Q. de. Correção com os pares: os efeitos do processo da correção dialogada na aprendizagem da escrita em língua inglesa. 2001. 340 f. Tese (Doutorado em Linguística Aplicada) - Faculdade de Letras, Universidade Federal de Minas Gerais, Belo Horizonte, 2001.

FIGUEIREDO, F. J. Q. de. Semeando a interação: a revisão dialógica de textos escritos em língua estrangeira. Goiânia: Ed. UFG, 2005.

FIGUEIREDO, F. J. Q. A aprendizagem colaborativa de línguas: algumas considerações conceituais e terminológicas. In: FIGUEIREDO, F. J. Q. de. (Org.). A aprendizagem colaborativa de línguas. Goiânia: Ed. UFG, 2006. p. 11-45.

FIGUEIREDO, F. J. Q. de.; ASSIS, N. A. L. A auto-estima e a atitude quanto à escrita na revisão colaborativa. In: FIGUEIREDO, F. J. Q. de. (Org.). A aprendizagem colaborativa de línguas. Goiânia: Ed. da UFG, 2006. p. 165-199.

FIGUEIREDO, F. J. Q. de.; OLIVEIRA, E. C. de. Sobre métodos, técnicas e abordagens. In: FIGUEIREDO, F. J. Q. de. (Org.). Formação de professor de línguas estrangeiras: princípios e práticas. 2. ed. rev. ampl. Goiânia: Editora UFG, 2017.

FREITAS, G. G. de. A produção textual em Escrita das Línguas de Sinais (ELiS): um contraste entre a escrita individual e a escrita colaborativa realizadas por alunos surdos. 2016. 147 f. Trabalho de Conclusão de Curso (Licenciatura em Letras: Libras) Faculdade de Letras, Universidade Federal de Goiás, Goiânia, 2016.

FREITAS, G. G. de.; FIGUEIREDO, F. J. Q. de. O processo de colaboração na produção de textos em escrita das línguas de sinais (ELiS): um estudo sobre as interações entre alunos surdos. Pensares em Revista, São Gonçalo-RJ, n. 14, p. 52-73, 2019.

GOMES, V. M. A.; RIOS, L. M.; OLIVEIRA, A. A. de. Produção Oral. In: FIGUEIREDO, F. J. Q. de. (Org.). Formação de professor de línguas estrangeiras: princípios e práticas. 2. ed. rev. ampl. Goiânia: Editora UFG, 2017.

HALL, J. K. Classrrom interaction and language learning. Ilha do Desterro, Florianópolis, n. 41, p. 17-39, 2001. 
HATCH, E. M. Discourse analysis and second language acquisition. In: HATCH, E. M. (Org.). Second language acquisition: A book of readings. Rowley: Newbury House, 1978, p. 401-435.

HIGOUNET, C. História concisa da escrita. São Paulo: Parábola Editorial, 2003.

KRASHEN, S. D. The monitor model for second-language acquisition. In: GINGRAS, R. C. (Org.). Second-language acquisition \& foreign language teaching. Washington: Center for Applied Linguistics, 1978. p. 1-26.

MOREIRA, H.; CALEFFE, L. G. Metodologia de pesquisa para o professor pesquisador. 2. ed. Rio de Janeiro: Lamparina, 2008.

OLIVEIRA-SILVA, C. M. de. A aprendizagem colaborativa de inglês instrumental por alunos surdos: um estudo com alunos do curso de Letras: Libras da UFG. 2017. $286 \mathrm{f}$. Tese (Doutorado em Letras e Linguística) - Faculdade de Letras, Universidade Federal de Goiás, Goiânia, 2017.

PAIVA, V. L. M. O. Aquisição de segunda língua. São Paulo: Parábola Editorial, 2014.

PIRES, V. O. D. A aprendizagem coletiva de língua portuguesa para surdos através das interações em língua de sinais. Revista Brasileira de Linguística Aplicada, Belo Horizonte, v. 14, n. 4, p. 987-1014, 2014.

REZENDE, M. V. de. Aprendizagem colaborativa e mediação pedagógica em curso de extensão universitária. Revista Texto Livre: Linguagem e Tecnologia. Belo Horizonte, v. 7, n. 1, p. 68-83, 2014.

RODRIGUES, K. A. Os efeitos dos estágios de planejamento e de revisões individual e colaborativa: a construção de textos escritos em língua inglesa por alunos adolescentes. In: FIGUEIREDO, F. J. Q. de. (Org.). A aprendizagem colaborativa de línguas. Goiânia: Ed. da UFG, 2006. p. 231-254.

SKLIAR, C. A surdez: um olhar sobre as diferenças. In: SKILIAR, C. (Org.). Porto Alegre: Mediação, 1998.

SILVA, S. V. da. O processo ensino-aprendizagem de linguas em teletandem: um estudo na área de Turismo. 2012. 293 f. Tese (Doutorado em Letras e Linguística) Faculdade de Letras, Universidade Federal de Goiás, Goiânia, 2012.

SILVA, G. M. da. O processo de ensino-aprendizagem da leitura em uma turma de alunos surdos: uma análise das interações mediadas pela Libras. Revista Brasileira de Linguística Aplicada, Belo Horizonte, v. 14, n. 4, p. 905-934, 2014.

SWAIN, M, Communicative competence: Some roles of comprehensible input and comprehensible output in its development. In: GASS, S. M.; MADDEN, C. C. (Org.). Input in second language acquisition. Rowley: Newbury House, 1985. p. 235-252. 
TORRES, P. L.; IRALA, E. Aprendizagem colaborativa: teoria e prática. In: TORRES, P. L. (Org.). Complexidade: redes e conexões na produção do conhecimento. Curitiba: SENARPR, 2014, v. 1, p. 61-93.

VYGOTSKY, L. S. A formação social da mente: o desenvolvimento dos processos psicológicos superiores. Tradução José Cipolla Neto, Luiz Silveira Menna Barreto, Solange Castro Afeche. 7. ed. São Paulo: Martins Fontes, 2007.

WOBETO, R. Produção colaborativa de textos escritos em língua inglesa: um estudo de caso. 2012. 159 f. Dissertação (Mestrado em Letras e Linguística) - Faculdade de Letras, Universidade Federal de Goiás, Goiânia, 2012.

WOOD, D.; BRUNER, J. S.; ROSS, G. The role of tutoring in problem solving. Journal of Child Psychology and Psychiatry, v. 17, p. 89-100, 1976. 

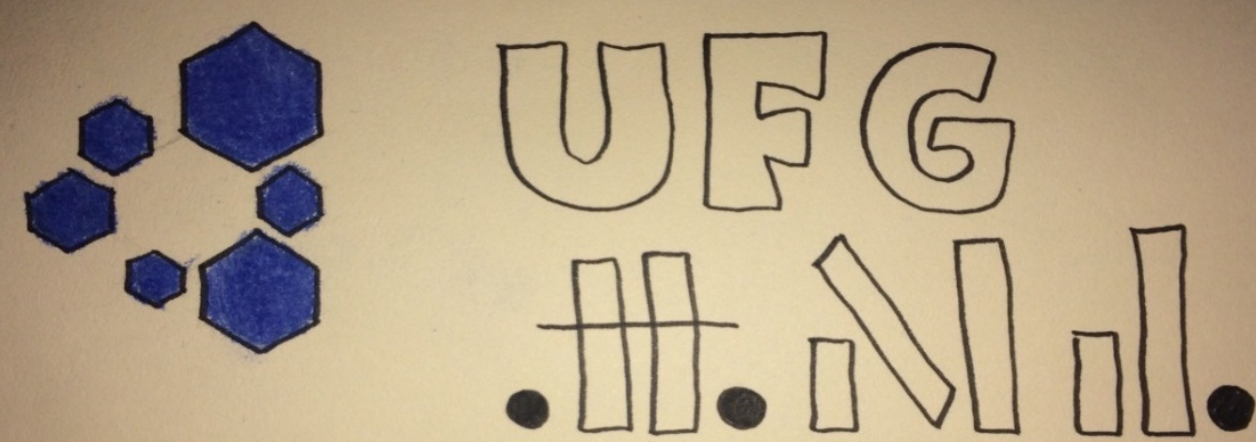

Queridos (as) Alunos(as),

E com imensa ategria que convidamos todos os alunos do Ensino Médio a participarem do Espaço das profissóes, ofere. cido pela Uni versidade Federal de Goias. Se wocês têm so. nhos, aqui é o hegar ideal para corneçarem a realizá-los.

Pois vocês terāo contato com alunos de diversos cursos, que poderão ajudá-los a tirar duividas para fazerem a melhor escolha em sua carreira profissional. O Evento acontecerá

em toda Universidade, nos dias 25 e 26 de jürho, das 8:00 as 20:00 h.

$$
\text { Aguardarnos vocês!!! }
$$

1. 四长 $T$,

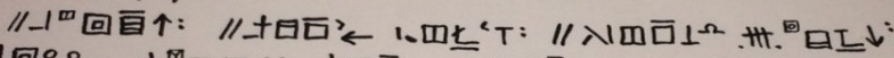

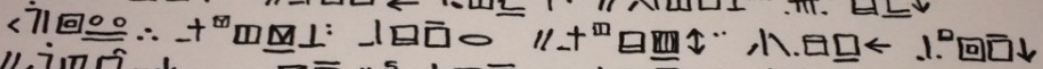

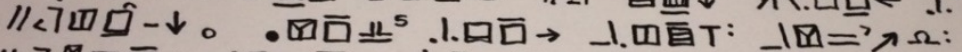

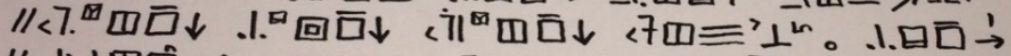

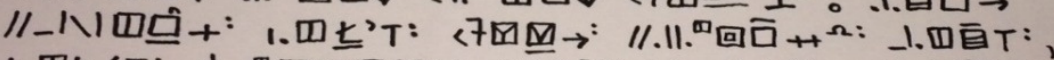

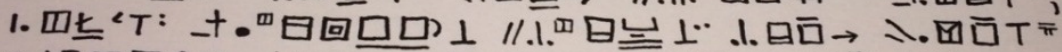

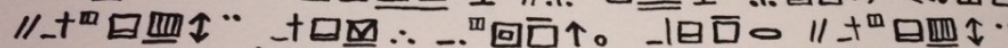

八. 分므 <17....1..25,26 /1.t.

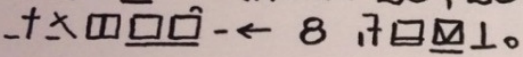

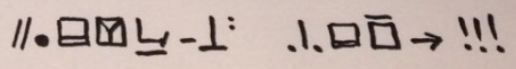

